\title{
Advancing social work professionalism: Standards for management and leadership in Aotearoa New Zealand
}

\author{
Mike Webster, David McNabb, and John Darroch
}

Mike teaches social work organisations and management in the School of Counselling, Human Services and Social Work at The University of Auckland. He is a registered social worker, and the convenor of the ANZASW managers and leaders interest group.

David is a registered social worker and a Lecturer in the Department of Social Practice at Unitec Institute of Technology in Auckland, where he was formerly Head of Department. He is President of the Council for Social Work Education in Aotearoa New Zealand.

John is a social work student currently doing his Master's at Auckland University. He has a passion for issues of social justice and how the social work profession can be a force for change.

\section{Abstract}

In 2004, management was recognised by the International Federation of Social Workers (IFSW) as one of 13 'core purposes' of the global profession. Taking that recognition as a starting point, this article advances the notion that the pre-eminent function of management in social work organisations is to serve, advocate for and integrate the remaining 12 purposes. We further propose that these 12 purposes express the profession's commitment to human rights and social justice as social work's distinctive values - that social justice has an organisational dimension.

Proceeding from that philosophical base, this paper introduces a research project to develop standards for social work management and leadership uniquely designed for Aotearoa New Zealand. The authors suggest that the IFSW core purpose statement informs and underpins the project. Standards developed by the profession in the United States and England are reviewed and elements drawn from those sources assessed for potential application to New Zealand. The concepts of leadership and management are examined to determine whether they are interchangeable terms, while noting that in the two overseas jurisdictions leadership is privileged. The article concludes by way of an introduction to the preliminary findings of the research project for future treatment.

\section{Introduction}

In 2004, the International Federation of Social Workers (IFSW) designated management as one of social work's 13 'core purposes' (Sewpaul \& Jones, 2005). To grasp management as a core purpose of the global profession means that we must also understand the context in which it is set - that is, the other 12 purposes. Management exists 'to plan, organise, administer and manage programmes and organisations dedicated to any of [those] purposes' (Sewpaul \& Jones, 2005, p. 219). Considered as a field of practice, therefore, management 
needs to be explored from the perspective of the profession's classic ecological or systems framework (Bronfenbrenner, 2005; Jarvis, 2009). In addition, the authors of this paper suggest that management must be understood as serving and advocating for the implementation of the other purposes within their organisational context. Practitioners who happen to be managers are no less social workers than frontline staff engaged in the 'nitty-gritty' of service delivery to marginalised populations in our communities. We argue that advocacy has an organisational dimension.

The authors offer a systemic perspective of social work in which human rights and social justice underpin those core purposes. Ife (2010) suggests that social justice is legitimately located in organisational structures. The challenge, then, for management is posed in the questions: how do managers advocate for social justice in organisational terms? How does management serve the values of the profession? Social work ethics apply as much to management as they do to the profession's commitment to challenging the structures in society that contribute to social exclusion, marginalisation and disempowerment (Aotearoa New Zealand Association of Social Workers [ANZASW], 2008).

This paper is the first of three presenting the authors' collaborative research project designed to develop standards for management and leadership in social work organisations, uniquely designed for Aotearoa New Zealand. The current article introduces the project and defines its parameters. A second article will report and discuss research findings on the proposed standards. A third will respond to the question: are social work management and leadership distinctive? The project builds conceptually on the work of Vicki Hirst who initiated and coordinated the ANZASW Supervisors Interest Group for several years and from which professional supervision standards were established for Aotearoa New Zealand.

This paper draws on two literature streams to inform the development of the proposed standards. The first stream derives from the overarching framework located in the IFSW's designation of management as a 'core purpose' of the profession, as noted earlier (Sewpaul \& Jones, 2005). We also explain how this paper treats leadership and management by considering whether they carry synonymous or differentiated meanings. From that global perspective, and in order to inform a New Zealand discussion, we develop a second stream which describes how professional social work bodies in the United States and England have contextualised the IFSW statements. The article assesses how the IFSW's management core purpose statement together with the two national statements might influence New Zealand thinking on social work management and leadership.

A seminal commitment to organisationally-applied social justice underpins the project. Unlike the wider management literature, academic and professional social work consideration of this field of enquiry is in its early stages, and may learn from management scholarship discourse. As an example, Zhang, Lepine, Buckman, and Feng (2014) identify organisational justice as referring to perceptions of fairness expressed as equitable outcomes for workers as the result of ethical, respectful and honest processes (p.677) - all values which resonate with the social work profession.

As the discussion unfolds, it will also become apparent to the reader that indigenous perspectives - integral to social work in Aotearoa New Zealand - are either largely absent or have nominal consideration from the international sources. The sole reference in the 
IFSW's 'core purpose' statement identifies the need for 'recognition and development of indigenous or locally specific social work education and practice from the traditions and cultures of different ethnic groups and societies, insofar that such traditions and cultures do not violate human rights' (Sewpaul \& Jones, 2005, p.220). In constructing standards for New Zealand, the authors propose that how the marginalisation of indigenous people of the land is addressed becomes a crucial measure of effective human rights and social justice. Applying Linda Tuhiwai Smith's (2005, p.87) perspective that researchers must 'privilege indigenous knowledges, voices, experiences, reflections' we will argue that the danger exists of setting up an adversarial framework between human rights/social justice on one side and indigenous values on the other. We aim for integration not subservience. This approach may enable a unique construction of social work leadership and management to emerge from this country.

\section{An overarching global framework}

The global framework is offered by social work's 13 core purposes (Sewpaul \& Jones, 2005), the IFSW Statement of Ethical Principles (IFSW, 2004), and human rights and social justice as defining identities of the profession (Ife, 2010; National Association of Social Workers [NASW], 1996). The IFSW proposes that ethical principles embodied in the Statement are applicable to social work organisations. The Federation also argues that practitioners are ethically obligated to enable the expression of those principles in their employing organisations.

Consistent with Ife (2010), it is striking that the Statement (IFSW, 2004) contains only two categories of principles:

\subsection{Human Rights and Human Dignity}

Social work is based on respect for the inherent worth and dignity of all people, and the rights that follow from this. Social workers should uphold and defend each person's physical, psychological, emotional and spiritual integrity and well-being.

\subsection{Social Justice}

Social workers have a responsibility to promote social justice, in relation to society generally, and in relation to the people with whom they work (IFSW, 2004, n.p.).

Section 5 of the IFSW Statement sets out expected guidelines on professional conduct. Of these, 5.12 is relevant to this paper:

Social workers should work to create conditions in employing agencies and in their countries where the principles of this statement and those of their own national code (if applicable) are discussed, evaluated and upheld (IFSW, 2004, n.p.).

The lucidity of the IFSW'S (2004) description of human rights cited above is not however matched by a similar clarity in respect of social justice. The definition proposed by the IFSW presents as a statement, even an appeal. Recognising the challenge of finding a commonly accepted 'specific value' for the profession, Stewart (2013, p.160) - admittedly writing from a US perspective - suggests that the NASW's (1996) social justice statement offers such a definition:

Ethical Principle: Social workers challenge social injustice.

Social workers pursue social change, particularly with and on behalf of vulnerable and op- 
pressed individuals and groups of people. Social workers' social change efforts are focused primarily on issues of poverty, unemployment, discrimination, and other forms of social injustice. These activities seek to promote sensitivity to and knowledge about oppression and cultural and ethnic diversity. Social workers strive to ensure access to needed information, services, and resources; equality of opportunity; and meaningful participation in decision making for all people (NASW, 1996, as cited in Stewart, 2013, p.165).

Managers and leaders who are also registered social workers in New Zealand must engage with their staff in ways which recognise their human rights and dignity and are expressed through social justice ideals. This article will argue that social justice as the profession's defining value is applied equally to the organisational context as it is to marginalised groups in society.

We argue that social work's 12 core purposes other than management (Sewpaul \& Jones, 2005, p. 219) are a collective, cogent expression of social justice ideals and actions. Ife (2010) suggests that social justice is as applicable to the interaction of social workers with 'colleagues, managers, students and other agencies' (p. 158) as it is to their professional practice. He thus places social justice - the profession's 'central organising value' (Marsh, 2005 , p. 293) - at the centre of organisational structures, the context in which social work leadership and management are exercised. We therefore propose that the values and actions mandated by social justice legitimately inform leadership and management standards. The implications for agencies, practitioners and clients of social justice applied to leadership and management will become clear in the second article.

Figure one. Social work's core purposes.

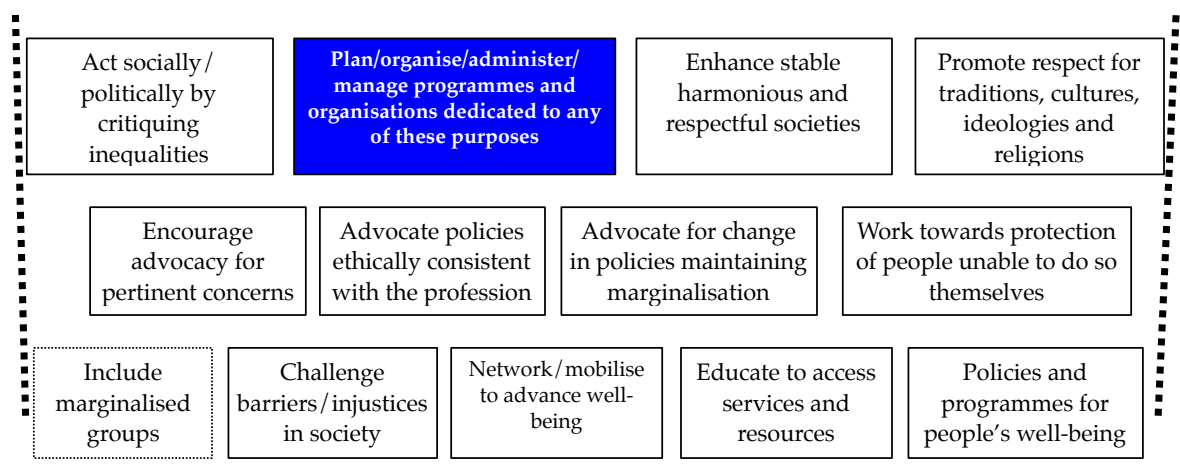

Core purposes and domains of social work

(Sewpaul \& Jones, 2005)

Social justice

Human rights

(IFSW, 2012; Ife, 2010; NASW, 1996)

The authors of this article further assert that the prime purpose of leadership and management standards must be to implement social justice as a practical organisational policy. Ten- 
sions will inevitably emerge as social justice as a professional value is faced with neoliberal ideology. Trnka and Trundle (2014) suggest that neoliberalism is predicated on notions of a shrinking state mandate, deregulation and privatisation, faith in the market as governing society, and personal choice and freedom (p.137). Citing Miller and Rose (2008, p.18) Trn$\mathrm{ka}$ and Trundle (2014, p.138) portray the development of personal choice and freedom as neoliberal 'responsibilisation': the idea of 'autonomous and responsible individuals, freely choosing how to behave and act' (2014, p.138.) While beyond the scope of the current article, the implications of this thinking on the state's social contract with citizens in constructing standards for social work leadership and management are profound. One practical manifestation is seen in the neoliberal management dictum to 'let managers manage' (see, e.g., Norman, 2001). The place of professional ethics, standards and identity in that scenario is an issue that social work will have to address.

Kurt Lewin (1952) famously wrote: 'There is nothing more practical than a good theory' (p. 169). If we are to inform leadership and management standards through an underpinning social justice lens, Lewin's enduring statement must be capable of implementation. This notion connects us to the second literature stream in which this paper considers leadership and management thinking in the United States and England.

Before exploring these themes, consideration is given to the issue posed by the question: are 'leadership' and 'management' interchangeable terms? May we construct the proposed standards by treating leadership and management as synonymous or interchangeable terms, or is there scope - or indeed a need - to distinguish between them?

\section{Leadership and management: Interchangeable terms?}

The intention of this article to lay a theoretical foundation for the research project to develop leadership and management standards for the profession in New Zealand requires consideration of how the authors conceptualise leadership and management. Divergent perspectives on this issue are equally evident in the social work and wider management and leadership literature. At one end of a continuum, unequivocal statements that the two terms are interchangeable are made; an example is found in the well-recognised British social work management text Management in Social Work (Coulshed, Mullender, Jones, \& Thompson, 2006.) From the wider management and leadership writing, we may note, for example, Zaleznik's (2010) assertion that there is a radical difference. The suggestion that management is essentially transactional in nature whereas leadership functions transformationally is endorsed by a number of leadership scholars such as Bass and Bass (2008); Bass and Avolio (1993); Bennis and Nanus (1985) and Burns (1978). In this view, transformational leaders build or change culture but transactional leaders operate within existing cultural norms (Bass \& Avolio, 1993).

Whether social work leadership and management should be distinctively treated is a moot point. The authors of this paper suggest value is found in Mackenzie's (1969) proposition, as cited in Bass and Bass (2008, p. 655), that management actions - Fayol's (1967) oft-cited functions of planning, organising, leading and controlling - are concerned with 'things': managing executive details; decision-making; allocating work to achieve the organisation's objectives; designing organisational structure and job descriptions; determining lines of 
accountability and the like. Leadership, in contrast, is seen as interacting with 'people', requiring communication skills to influence people to achieve desired objectives; purposeful action; motivating; conflict resolution; managing change; selecting, training and developing people and so on (Mackenzie, 1969, pp. 81-86).

Even in this treatment we note the blurring of boundaries in that Fayol (1967) perceives leadership actions as subsumed in management. To resolve this blurring, the authors of this paper adopt Grint's (2005) approach which proposes that leadership actions are socially constructed by the problems and challenges that organisations face. 'Tame' or familiar difficulties are appropriately addressed by management actions, but 'wicked' problems, with no ready solution, and critical problems engendered by a crisis with a demand for rapid resolution, call for leadership actions (Grint, 2005, p. 1473). We suggest that Grint's thinking illustrates the divergence between transactional management and transformational leadership (Bass \& Bass, 2008).

A useful social work interpretation of management, leadership and governance reflecting Mackenzie's (1969) thinking cited earlier is located in the Scottish Social Work Inspection Agency's [SWIA](2010) Guide to Leadership:

Generally, we use 'management' to mean overseeing the operation of the service, accomplishing goals and achieving tasks. The term 'leadership' spans a wider remit that includes influencing and inspiring others, generating ideas and defining a strategy and vision. The term 'governance' means the systems, processes, controls and accountabilities and decision making at the heart of and at the highest level of an organisation. (SWIA, 2010, p. 7)

The 'wider remit' leadership statement makes a distinction between leadership and management. The Guide nevertheless qualifies that distinction by noting that, in practice, overlap between the two is likely. Leaders may be required to manage tasks and projects; managers may need to influence and inspire others. A situational approach - 'behaviours that match the situation' (Fisher, 2009, p.360) - is evident in the Guide's thinking: 'what matters is getting the right balance for particular circumstances' (SWIA, 2010, p. 7).

\section{Leadership and management standards for social workers: An overview from the United States and England}

\section{United States}

Competencies for social work managers in the US were developed by the Network for Social Work Managers (NSWM) and first approved by the NSWM Board in 1997. They were revised in 2004 (Wimpfheimer, 2004) and again in 2013 (Hassan, Waldman, \& Wimpfheimer, 2013). Wimpfheimer (2004) suggests that the impetus for developing management competencies in the US arose from inadequate training for the task. In common with other authors (see, e.g., Hopkins \& Hyde, 2002) Wimpfheimer notes that many managers in the social work profession are promoted from frontline positions. Fortunate new managers were those who experienced good role models, good supervision and were oriented towards management practice. Critically, however, 'these neophytes to management are expected to know what to do and how to do it with little training and support' (Wimpfheimer, 2004, p. 46). Anecdotally, such a statement could be applied with little or no amendment to the Aotearoa New Zealand context. 
In its 2013 iteration, four domains are identified in the NSWM competencies: executive leadership, resource management, strategic management and community collaboration. Each domain comprises specific competencies and associated performance indicators, language which suggests the influence of new public management (NPM) (Hood, 1991), familiar to social work managers in Aotearoa New Zealand since the late 1980s. The standards are evidenced by 21 demonstrated competencies which the network believes should be demonstrated by managers in social work agencies (Hassan et al., 2013). The competencies have been used in the past to develop a 'certified social work manager' credential (Wimpfheimer, 2004) although this is no longer available to social workers in the US.

The NSWM's 2013 statement of competencies privileges the leadership component. In recent years the competencies model has become dominant in management literature and practice (see, e.g., Quinn, 2002). Wimpfheimer (2004, p.49) defines competencies as the 'ability and knowledge' to demonstrate a specific skill such as advocacy (p. 49). Although managers are expected to perform across the board in the range of competencies set out in each domain, Hassan et al. (2013) argue that leadership transcends the other domains and their respective competencies. They suggest that, as 'the most complex, critical and overarching competency' (2013, p. 2) a key leadership capacity is the ability to exercise self-awareness and the self-confidence required to build an organisational leadership group in which all the other management competencies are expressed. In reality, no single social work manager can demonstrate every competency.

The implications of the NSWM model in developing New Zealand social work leadership and management standards will be considered two-dimensionally. The first dimension is the pre-eminence of leadership accorded by the NSWM. The second relates to the competencies-based management model.

\section{England}

The professional capabilities framework (PCF) for social workers was developed out of social work reforms in England now administered by The College of Social Work (The College of Social Work, 2012c). In 2008, the Government commissioned the Social Work Task Force to conduct a thorough review of social work in England. This led to the report, Building $a$ Safe, Confident Future (The Social Work Taskforce, 2009), which set out 15 recommendations for improving and reforming social work. They were designed to enable social workers to benefit from high-quality education and training in responding to practice demands over the course of their careers.

The PCF covers nine domains: professionalism; values and ethics; diversity; rights, justice and economic well-being; knowledge; critical reflection and analysis; intervention and skills; context and organisations; and professional leadership (The College of Social Work, 2012b) (see Figure 2). Practice levels range from student to strategic social work educator / principal social worker/strategic social work manager. The domains and the level descriptors include guidance targeted at leaders and managers. The standards for employers of social workers in England (Local Government Authority [LGA], 2014) is a more recent document that builds on work done by the social work reforms and targets the responsibilities employers have in ensuring quality social work outcomes. 
Figure two. Professional capabilities framework for social workers in England.

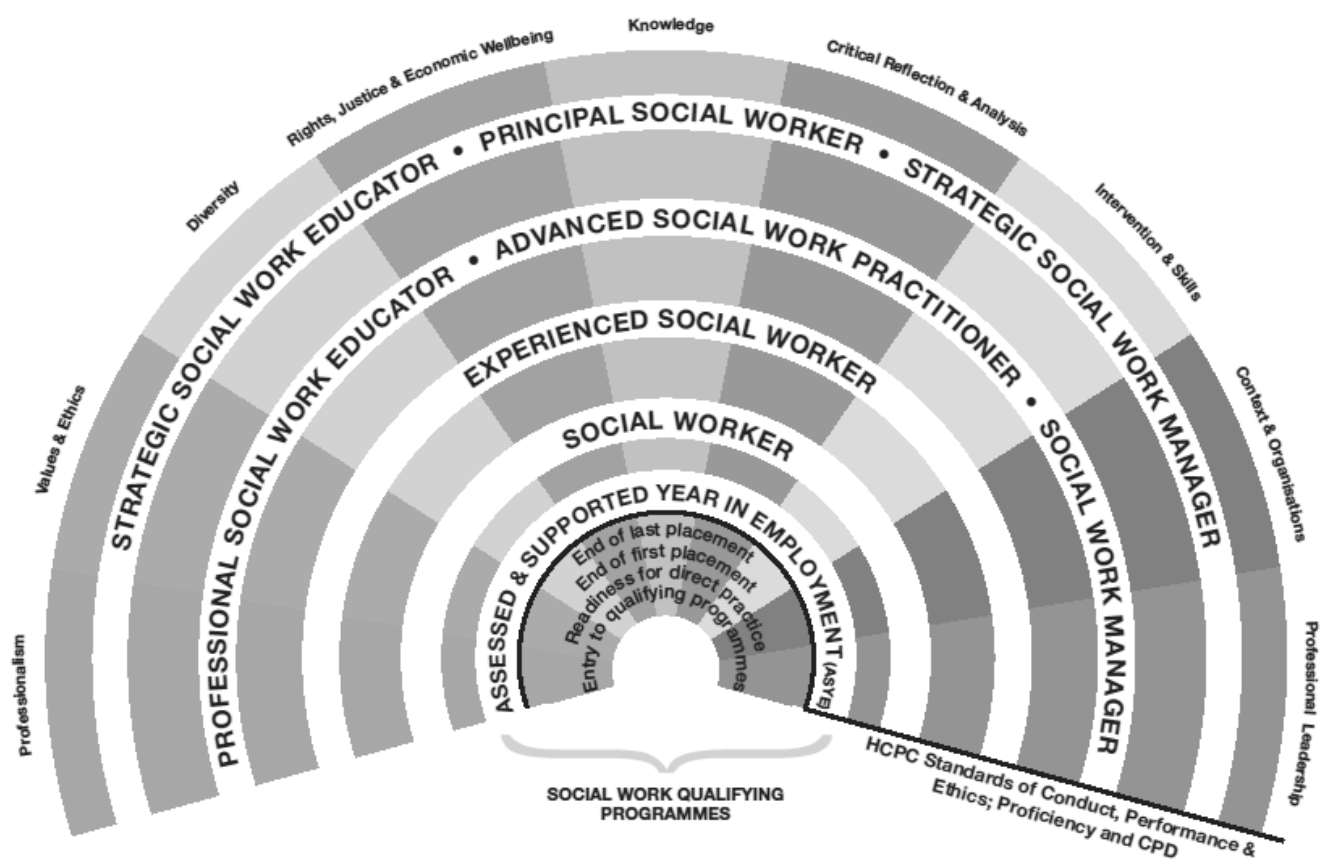

(Source: The College of Social Work. (2012c). Professional capabilities framework for social workers. Retrieved from http: / / www.tcsw.org.uk/ resources / reform-resources /\#pcf.

The strategic level of the PCF includes three developmental pathways for social workers: strategic social work educator, principal social worker and strategic social work manager (The College of Social Work, 2012a), covering practice across the sector. These pathways place priority on a comprehensive approach to leadership and management for a strong social work sector. Expectations of strategic social work leaders and managers include upholding professional values by ensuring the views of service users are represented, implementing the standards for employers or social workers, ensuring social work counsel informs decision making in organisations 'supporting the organisation to do things right and also to do the "right thing" (The College of Social Work, 2012d, p. 3). There is also an expectation that a human rights and ethical framework will be used by strategic social work leaders and managers. Social workers operating at a strategic level are key players in the social work sector, leading and initiating change within and across organisations to improve quality and outcomes (The College of Social Work, 2012a, p. 3).

The standards for employers of social workers in England (LGA, 2014) were developed by the Social Work Reform Board between 2009 and 2012. The development of standards for employers of social workers in England highlights the responsibility of employers and funders in setting out proficient social work practice. Sets of expectations tend to empha- 
sise the responsibilities of practitioners without balancing those with the responsibilities of employers and funders.

The institution of the PCF and standards for employers of social workers in the English reforms provide a useful starting point to summarise their potential application to social work leadership and management in Aotearoa New Zealand. Together with the NSWM leadership and management standards and the Scottish initiatives and, within the overarching IFSW Statement of Ethical Principles (IFSW, 2004), this paper will now consider those implications in its summative section. This section will also briefly describe the research project into standards for the profession in New Zealand undertaken by two of the authors, and to which this paper serves as a conceptual introduction. The findings and their application form a second article.

\section{Leadership and management standards for social workers: Applying the global perspective to Aotearoa New Zealand}

In evaluating the principles underpinning social work leadership and management and their practical application in the US and England, we suggest that certain elements are appropriately applied to New Zealand. These elements are categorised under three headings:

1. The core purposes and non-negotiable ethical principles of the global profession (Ife, 2010; IFSW, 2004; Sewpaul \& Jones, 2005).

2. The pre-eminence of leadership? Implications for development of standards.

3. Asking questions and setting out standards: Professional and organisational dimensions.

\section{Core purposes and ethical principles of the global profession}

In an earlier paper, one of the authors argued that ethical considerations require that organisational activities including leadership actions must be integrated with the profession's ethical codes (Webster, 2014). Ethical integrity applies equally to leadership, management, and direct service delivery - a proposition already advanced in the introduction and global framework discussion opening this article.

We propose that the construction of leadership and management standards for the profession in Aotearoa New Zealand must embody conceptual and practical applications expressed in the IFSW's Statement (2004) regarding human rights and dignity, and social justice. Pursuant to the human rights and dignity commitment, leaders and managers, at any organisational level and whether in the state or not-for-profit sector, are ethically obligated to 'uphold and defend each [staff member's] physical, psychological, emotional and spiritual integrity and well-being' (IFSW, 2004, n.p.). Equally, leaders and managers are responsible for '[promoting] social justice in relation to the people with whom they work' (IFSW, 2004, n.p.).

We suggest that creating leadership and management standards is a multi-dimensional task. Standards are not ethical codes. Maintaining the fine balance between the prescriptive language characteristic of organisational codes of conduct and the language of integrity in codes of ethics will be challenging. However, wordsmithing represents only part of the challenge in devising standards. Unless practically applied, the standards run the risk of degenerating into statements of intent that do not become part of the organisational leadership and management culture. To address this risk, we propose that a critical function of 
professional and organisational working parties tasked with implementing the standards will be to examine how leadership and management can actively facilitate the other 12 core purposes (Sewpaul \& Jones, 2005) of the profession (Figure one).

Issues to be raised might include, for example, how leaders and managers:

- Act socially and politically by critiquing (organisational) inequalities

- Advocate for change in policies maintaining (workplace) marginalisation

- Network and mobilise to advance well-being of workers

In other words, leadership actions to influence and align professional and organisational culture with social justice are suggested, not prescriptive management instructions.

\section{The pre-eminence of leadership?}

As noted earlier, a review of the scenarios in the US and England suggests that the profession's thinking on management and leadership in those jurisdictions accords pre-eminence to leadership. The US NSWM model explicitly comments that 'leadership in many ways transcends all other competencies' (Hassan et al., 2013, p. 2). Nevertheless, the US NSWM model (Hassan et al., 2013) has embraced competency management thinking and treats leadership as a skill to be acquired. Hassan and his colleagues describe competencies as a 'robust array of intellectual, interpersonal, and technical skills' (2013, p. 2). In effect, such a formulation integrates personal capacity with knowledge and skill acquisition. The personal capacity perspective is reminiscent of trait leadership thinking, which proposes that certain traits differentiate leaders from other individuals (Colbert, Judge, Choi, \& Wang, 2012). We propose that the apparent integration of social work leadership with trait thinking and the business-based competency approach needs clarification.

This article suggests that, of the two jurisdictions, the profession in England arguably presents the most systemic perspective on the leadership and management of social care providers by acknowledging a strategic role for leaders and managers in ensuring quality social work practice. English colleagues argue that it is essential that social work leaders and managers are actively engaged in the social work sector and the organisational context. Further evidence of this is seen in the field of professional leadership claiming its own domain among the nine that make up the full range of social work professional practice. The professional leadership domain 'take[s] responsibility for the professional learning and development of others through supervision, mentoring, assessing, research, teaching, leadership and management' (The College of Social Work, 2012b, p. 3).

The English model's professional leadership domain immediately suggests possible application to Aotearoa New Zealand. The SWRB, as the regulator for the social work profession, ensures accountability for the behaviour and practice of registered social workers (SWRB, 2008, 2014) but does not have control over the employment context which is critical for supporting quality practice and outcomes. While it is not usual in Aotearoa New Zealand for professional registration bodies to regulate employers and funders, it highlights the need for comprehensive governance of a relatively complex sector if there is to be an assurance of quality social work outcomes.

The political background of neo-liberal policies and managerialism in Aotearoa New Zealand has reinforced individual consumer responsibility and individual social worker 
responsibility to the neglect of state and employer responsibility for our sector (Harington \& Beddoe, 2014). This context requires a comprehensive sector-wide response to ensure quality social work outcomes, as suggested by the social work reforms in England (McNabb, 2014). We could do well to work with the content of the professional leadership domain and the strategic-level descriptor of the professional capabilities framework for social workers to develop our own professional standards for social work managers and leaders in Aotearoa New Zealand. Any standards should be set in the context of expectations of the whole social work sector in acknowledgement of the broad range of structural relationships that are required to achieve sector-wide outcomes.

\section{Asking questions and setting out standards: Professional and organisational dimensions}

An analysis of the professional discourse in England - but not of the US - reveals a striking distinction: the extensive use of questions as an alternative to prescriptive statements. This paper offers a summative statement by proposing that the enquiry mode epitomised by asking questions, a 'community of enquiry' (LaMendola, Ballantyne, \& Daly, 2009), promises to be a common thread in developing leadership and management standards for Aotearoa New Zealand. That enquiry mode presupposes that leaders and managers are not to be seen as the proverbial sage on the stage (King, 1993) but in the empowerment philosophy of practice characteristic of social work, constructivist guides on the side (King, 1993). We use research into management and leadership, but filter that body of knowledge through Payne's 'what works' $(2005,2014)$ approach to developing theory.

\section{Conclusion: A scaffolding statement}

The enquiry mode sets the scene for our second article which will report on research into the development of leadership and management standards specifically for Aotearoa New Zealand. As part of the overarching project to develop these standards, the perspectives of social workers who identified themselves as being in a leadership or management position or who had a specific interest in this area were gathered via two focus groups and a telephone interview. Following ethics approval, participants were recruited via an email to the ANZASW membership list. These social workers were asked a range of open-ended questions regarding the desirability of developing leadership and management standards and the content to be covered in the standards.

Preliminary analysis of data indicates a general consensus from participants that leadership and management standards would be of use to the profession and that elements of existing international standards could be included in these standards. Participants identified barriers to exercising professional leadership and management faced by social workers in such positions, and the tension between the realities of practice and the ideals presented by standards. Other concerns, such as the increasing presence of managers who were not from a social work background and who may not feel bound by social work standards were also raised by participants. These perspectives will be presented fully in the next article planned by the current authors.

\section{References}

Aotearoa New Zealand Association of Social Workers. (2008). Code of ethics (Rev. ed.). Christchurch: Aotearoa New Zealand Association of Social Workers. 
Attwood, M., Pedler, M., Pritchard, S., \& Wilkinson, D. (2003). Leading change: A guide to whole systems working. Bristol, UK: Policy Press.

Bass, B. M., \& Avolio, B. (1993). Transformational leadership and organizational culture. Public Administration Quarterly, 17(1), 112-121.

Bass, B. M., \& Bass, R. (2008). The Bass handbook of leadership: Theory, research, and managerial applications (4th ed.). New York, NY: Free Press.

Beddoe, L., \& Duke, J. (2013). Continuing professional development of registered social workers in New Zealand. Aotearoa New Zealand Social Work Review, 25(3), 35-49.

Bennis, W., \& Nanus, B. (1985). Leaders: The strategies for taking charge. New York, NY: Harper \& Row.

Bronfenbrenner, U. (Ed.). (2005). Making human beings human: Bioecological perspectives on human development. Thousand Oaks, CA: Sage.

Burns, J. M. (1978). Leadership. New York, NY: Harper and Row.

Colbert, A. E., Judge, T. A., Choi, D., \& Wang, G. (2012). Assessing the trait theory of leadership using self and observer ratings of personality: The mediating role of contributions to group success. The Leadership Quarterly, 23(4), 670-685. Retrieved from http:/ / dx.doi.org/10.1016/j.leaqua.2012.03.004.

Coulshed, V., Mullender, A., with Jones, D., \& Thompson, N. (2006). Management in social work (3rd ed.). Houndmills, UK: Palgrave Macmillan.

Fayol, H. (1967). General and industrial management (C. Storrs, Trans.). London: Pitman.

Fisher, E. A. (2009). Motivation and leadership in social work management: A review of theories and related studies. Administration in Social Work, 33(4), 347-367.

Grint, K. (2005). Problems, problems, problems: The social construction of 'leadership'. Human Relations, 58(11), 1467-1494.

Harington, P. R. J., \& Beddoe, L. (2014). Civic practice: A new professional paradigm for social work. Journal of Social Work, 14(2), 147-164.

Hassan, A., Waldman, W., \& Wimpfheimer, S. (2013). Human services management competencies: A guide for non-profit and for profit agencies, foundations, and academic institutions. Los Angeles, CA: The Network for Social Work Management.

Hood, C. (1991). A public management for all seasons? Public Administration, 69(1), 3-19.

Hopkins, K. M., \& Hyde, C. (2002). The human service managerial dilemma: New expectations, chronic challenges and old solutions. Administration in Social Work, 26(3), 1-15.

Ife, J. (2010). Human rights and social justice. In M. Gray, \& S. A. Webb (Eds.), Ethics and value perspectives in social work (pp. 148-159). Basingstoke, UK: Palgrave Macmillan.

International Federation of Social Workers. (2004). Code of ethics. Berne, Switzerland: International Federation of Social Workers.

Jarvis, P. (2009). Learning to be a person in society. Abingdon, England; New York: Routledge.

King, A. (1993). From sage on the stage to guide on the side. College Teaching, 41(1), 30-35.

LaMendola, W., Ballantyne, N., \& Daly, E. (2009). Practitioner networks: Professional learning in the twenty-first century. British Journal of Social Work, 39(4), 710-724. doi:10.1093/bjsw/bcp023.

Lees, A., Meyer, E., \& Rafferty, J. (2013). From Menzies Lyth to Munro: The problem of managerialism. British Journal of Social Work, 43(3), 542-558.

Lewin, K. (1952). Field theory in social science: Selected theoretical papers. London, England: Tavistock.

Local Government Authority. (2014). The standards for employers of social workers in England. Retrieved from http: / / www.local.gov.uk/ documents / 10180/6188796/ The+Standards+-+updated+July+01+2014/146988cc-d9c5-4 311-97d4-20dfc19397bf.

Mackenzie, R. (1969). The management process in 3-D. Harvard Business Review, 47(6), 80-87.

Marsh, J. C. (2005). Social justice: Social work's organising value. Social Work, 50(4), 293-294.

McLaughlin, H. (2009). What's in a name: 'Client', 'patient', 'customer', 'consumer', 'expert by experience', 'service user' —what's next? British Journal of Social Work, 39(6), 1101-1117. doi:10.1093/bjsw / bcm155.

McNabb, D. (2014). 30 years' membership and a 50th birthday-where to next for ANZASW? Aotearoa New Zealand Social Work Review, 26(2\&3), 61-71.

McNary, L. D. (2003). The term 'win-win' in conflict management: A classic case of misuse and overuse. Journal of Business Communication, 40(2), 144-159.

Miller, P., \& Rose, N. (2008). Governing the present: Administering economic, social and personal life. Malden, MA: Polity Press.

Munro, E. (2010). The Munro Review of child protection - part one: A systems analysis. London, England: Department for Education.

Munro, E. (2011). The Munro Review of child protection: Final report. London, England: Department for Education.

National Association of Social Workers. (1996). Code of ethics. Retrieved from http://www.naswdc.org/pubs/ code/code.asp.

Norman, R. (2001). Letting and making managers manage: The effect of control systems on management action in New Zealand's central government. International Public Management Journal, 4(1), 65-89.

Northouse, P. G. (2010). Leadership: Theory and practice (5th ed.). Thousand Oaks, CA: Sage.

Osborne, S. P., \& Brown, K. (2005). Change and innovation in public service organizations: Planned and emergent phenomena. Managing change and innovation in public service organizations (pp. 3-10). Abingdon, England; New York, NY: Routledge. 
Payne, M. (2005). Modern social work theory (3rd ed.). Chicago, IL: Lyceum.

Payne, M. (2014). Modern social work theory (4th ed.). Basingstoke, England: Palgrave Macmillan.

Quinn, R. E. (2002). Becoming a master manager: A competency framework (3rd ed.). New York, NY: Wiley.

Social Work Inspection Agency. (2010). Guide to leadership: Taking a closer look at leadership in social work services. Edinburgh, Scotland: Social Work Inspection Agency.

Senge, P. M. (1997). The fifth discipline. Measuring Business Excellence, 1(3), 46-51.

Sewpaul, V., \& Jones, D. (2005). Global standards for the education and training of the social work profession. International Journal of Social Welfare, 14(3), 218-230.

Smith, L. T. (2005). On tricky ground: Researching the native in the age of uncertainty. In N. K. Denzin \& Y. S. Lincoln (Eds.), The Sage handbook of qualitative research (pp. 85-107). Thousand Oaks, CA: Sage.

Social Work Inspection Agency. (2010). Guide to leadership: Taking a closer look at leadership in social work services. Edinburgh, Scotland: Social Work Inspection Agency.

Social Workers Registration Board. (2008). Code of conduct for social workers (2nd ed.) Retrieved from http: / / www. swrb.govt.nz/code-of-conduct.

Social Workers Registration Board. (2014). The SWRB 10 core competence standards (2nd ed.) Retrieved from http: / / www.swrb.govt.nz/policy.

Stewart, C. (2013). Resolving social work value conflict: Social justice as the primary organizing value for social work. Journal of Religion \& Spirituality in Social Work: Social Thought, 32(2), 160-176.

Taylor, F. W. (1967). The principles of scientific management. New York, NY: Norton.

The College of Social Work. (2012a). Advanced and strategic level descriptors. Retrieved from http:/ / www.tcsw.org. uk/uploadedFiles/PCF13NOVAdvancedLevelDescriptors\%20(2).pdf.

The College of Social Work. (2012b). Domains within the PCF. Retrieved from http: / / www.tcsw.org.uk/uploadedFiles/PCFDomainsNOV.pdf.

The College of Social Work. (2012c). Professional capabilities framework for social workers. Retrieved from http: / / www. tcsw.org.uk/ resources / reform-resources / \#pcf.

The College of Social Work. (2012d). The Professional Capabilities Framework: Advanced and strategic level descriptors. London, England: The College of Social Work. Retrieved from http:/ / www.tcsw.org.uk/uploadedFiles/ PCF13NOVAdvancedLevelDescriptors\%20(2).pdf.

The Social Work Taskforce. (2009). Building a safe, confident workforce: The final report of the social work taskforce. Retrieved from http: / / webarchive.nationalarchives.gov.uk/20130401151715/https: / www.education.gov.uk/ publications/standard/publicationdetail/page1/DCSF-01114-2009.

Trnka, S., \& Trundle, C. (2014). Competing responsibilities: Moving beyond neoliberal responsibilisation. Anthropological Forum, 24(2), 136-153.

Webster, M. (2014). A vision for social work leadership: Critical conceptual elements. In J. Duke, M. Henrickson \& L. Beddoe (Eds.), Protecting the public - Enhancing the profession. E tiaki ana $i$ te hapori-E manaaki ana $i$ nga mahi (pp. 79-92). Wellington, New Zealand: Social Workers Registration Board.

Wimpfheimer, S. (2004). Leadership and management competencies defined by practising social work managers - An overview of standards developed by the National Network for Social Work Managers. Administration in Social Work, 28(1), 45-56.

Zaleznik, A. (2010). Managers and leaders: Are they different? In J. McMahon (Ed.), Leadership classics (pp. 86-98). Long Grove, IL: Waveland Press.

Zhang, Y., Lepine, J. A., Buckman, B. R., \& Feng, W. E. I. (2014). It's not fair ... or is it? The role of justice and leadership in explaining work stressor-job performance relationships Academy of Management Journal, 57(3), 675-697. 